\title{
Polydeoxyribonucleotide Ameliorates Inflammation and Apoptosis in Achilles Tendon-Injury Rats
}

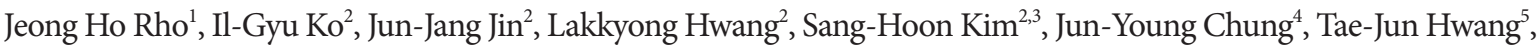 \\ Jin Hee $\mathrm{Han}^{6}$ \\ 'Department of Anesthesiology and Pain Medicine, Okcheon St. Mary's Hospital, Okcheon, Korea \\ ${ }^{2}$ Department of Physiology, College of Medicine, Kyung Hee University, Seoul, Korea \\ ${ }^{3}$ Department of Sport \& Health Care, College of Art \& Culture, Sangmyung University, Seoul, Korea \\ ${ }^{4}$ Department of Anesthesiology and Pain Medicine, Kyung Hee University Hospital at Gangdong, College of Medicine, Kyung Hee University, Seoul, Korea \\ ${ }^{5}$ Department of Medicine, Graduate School, Kyung Hee University, Seoul, Korea \\ ${ }^{6}$ Department of Anesthesiology and Pain Medicine, Kyung Hee University Medical Center, College of Medicine, Kyung Hee University, Seoul, Korea
}

Purpose: Adenosine $\mathrm{A}_{2 \mathrm{~A}}$ receptor agonist polydeoxyribonucleotide (PDRN) possesses an anti-inflammatory effect and suppress apoptotic cell death in several disorders. In this current study, the effect of PDRN on inflammation and apoptosis in rats with Achilles tendon injury was investigated.

Methods: von Frey filament test and plantar test were conducted for the determination of pain threshold. Analysis of histological alterations was conducted by hematoxylin and eosin staining. Immunohistochemistry for cleaved caspase-3-positive cells and cleaved caspase-9-positive cells was done. Enzyme-linked immunoassay was used to detect the concentrations of tumor necrosis factor (TNF)- $\alpha$, interleukin (IL)-6, and cyclic adenosine-3',5'-monophosphate (cAMP). Western blot was conducted to detect the protein levels of cAMP response element-binding protein (CREB), protein kinase A (PKA), Bcl-2-associated X (Bax), and B-cell lymphoma 2 (Bcl-2).

Results: PDRN treatment relieved mechanical allodynia and alleviated thermal hyperalgesia after Achilles tendon injury. TNF- $\alpha$ and IL- 6 concentrations were decreased by PDRN application. PDRN injection significantly enhanced cAMP concentration and phosphorylated CREB versus CREB ratio, showing cAMP-PKA-CREB pathway was activated by PDRN application. PDRN treatment inhibited percentages of cleaved caspase-3-positive cells and caspase-9-posiive cells and the suppressed Bax versus Bcl-2 ratio in Achilles tendon injury rats.

Conclusions: PDRN is probably believed to have a good effect on pain and inflammation in the urogenital organs. PDRN may be used as a new treatment for Achilles tendon injury.

Keywords: Achilles tendon; Polydeoxyribonucleotide; Inflammation; Apoptosis

- Research Ethics: This experimental procedure was approved by the Institutional Animal Care and Use Committee of Kyung Hee University (KHUASP [SE]-18-095).

- Conflict of Interest: No potential conflict of interest relevant to this article was reported.

\footnotetext{
- HIGHLIGHTS

- PDRN relieved mechanical allodynia and alleviated thermal hyperalgesia after Achilles tendon injury.

- PDRN reduced TNF- $a$ and IL- 6 concentrations and enhanced cAMP concentration and p-CREB to CREB ratio in Achilles tendon-injured rats. - PDRN inhibited percentages of cleaved caspase-3-positive cells and caspase-9-positive cells and suppressed Bax vs. Bcl-2 ratio in Achilles tendon injury.
}

Corresponding author: Jin Hee Han (iD http://orcid.org/0000-0003-0399-1148 Department of Anesthesiology and Pain Medicine, Kyung Hee University Medical Center, Kyung Hee University College of Medicine, 23 Kyungheedae-ro, Dongdaemun-gu, Seoul 02447, Korea E-mail: esthesi@khu.ac.kr

Submitted: October 5, 2020 / Accepted after revision: November 10, 2020 


\section{INTRODUCTION}

Achilles tendon injury causes pain and disability in athletes and in the public. Long-term change in tendons affects muscle atrophy, build-up of connective tissue in the muscles, formation of adhesions, decreased functional capacity, and ultimately quality of life and medical costs [1]. Damaged tendon induces a local inflammation response mediated by the release of proinflammatory cytokines. Proinflammatory cytokines comprising tumor necrosis factor (TNF)- $\alpha$ and interleukin (IL)- 6 are secreted primarily by inflammatory cells and are found at high level at the injured site [2].

Delayed treatment of Achilles tendon injury leads to tissue degenerative changes due to excessive apoptotic activity [3]. Caspases exert critical role in the process of programmed cell death and act as protease enzyme. Amon the caspases, caspase- 3 plays as executioner caspases, while caspase- 8 and caspase- 9 act as initiate caspase [4]. The cleaved form of caspases activates the apoptosis pathway, causing DNA degradation, which in turn leads to cell death [4]. B-cell lymphoma 2 (Bcl-2) family include antiapoptotic proteins, such as Bcl-2, which suppress apoptotic process and pro-apoptotic proteins, such as $\mathrm{Bcl}$ 2-associated X (Bax), which promote apoptosis [5]. Depending on the status of pro-apoptotic and antiapoptotic proteins, the mitochondrial response to apoptosis stimulation is different [6]. When pro-apoptotic proteins are more active than antiapoptotic proteins, apoptosis process on tendon begins and eventually promotes tendon damage $[7,8]$.

Nonsteroidal anti-inflammatory drugs (NSAIDs) are used for Achilles tendon damage. However, previous studies have found that long-term use of oral NSAIDs can cause side effects such as gastrointestinal bleeding, ulcers, and perforation. Therefore, there is a need for a new pharmacological therapy that has fewer side effects and can effectively treat Achilles tendon damage.

Adenosine receptors are receptors that have adenosine as an endogenous ligand and are classified as purinergic $G$ proteincoupled receptors. Four types of adenosine receptors such as $A_{1}, A_{2 A}, A_{2 B}$, and $A_{3}$ exist in human immune/inflammatory cells. Activation on adenosine $\mathrm{A}_{2 \mathrm{~A}}$ suppresses the secretion of proinflammatory cytokines in a variety of disease conditions [9]. The adenosine $\mathrm{A}_{2 \mathrm{~A}}$ receptor agonist polydeoxyribonucleotide (PDRN) possesses anti-inflammatory effect by inhibiting the secretion of proinflammatory cytokines $[10,11]$. PDRN is known to suppress the secretion of proinflammatory cytokines and apoptotic cell death in many inflammatory disorders $[12,13]$.

The effect of PDRN on inflammation and apoptosis in rats with Achilles tendon injury was evaluated in this current study. For this study, von Frey filament test for pain threshold and plantar test for heat threshold were conducted. Analysis of histological alterations was conducted by hematoxylin and eosin (H\&E) staining. Immunohistochemistry for cleaved caspase3-positive cells and cleaved caspase-9-positive cells was performed. Enzyme-linked immunoassay (ELISA) was used to detect the concentrations of TNF- $\alpha$, IL- 6 , and cyclic adenosine3,5'-monophosphate (cAMP). The expressions of cAMP response element-binding protein (CREB), protein kinase $A$ (PKA), Bax, and Bcl-2 were measured by western blot analysis.

\section{MATERIALS AND METHODS}

\section{Animals and Grouping}

Male Sprague-Dawley rats weighing $230 \pm 5 \mathrm{~g}$ (8 weeks old) were managed in a laboratory with temperature and light control. The rats were classified into the 5 groups $(n=8$ in each group): control group, Achilles tendon injury group, Achilles tendon injury and $2 \mathrm{mg} / \mathrm{kg}$ PDRN-applied group, Achilles tendon injury and $4 \mathrm{mg} / \mathrm{kg}$ PDRN-applied group, Achilles tendon injury and $8 \mathrm{mg} / \mathrm{kg}$ PDRN-applied group.

\section{Induction of Achilles Tendon Injury}

Surgery was conducted to damage the Achilles tendon, like the method described below [14]. After anesthetized with Zoletil $50(10 \mathrm{mg} / \mathrm{kg}$, intraperitoneally; Vibac Laboratories, Carros, France), the tibia area of the right foot was manually trimmed and a longitudinal skin incision (approximately $0.5 \mathrm{~cm}$ ) was made to access the Achilles tendon. A rubber-coated support was inserted deep in the Achilles tendon, and partial width ( $50 \%)$ was excised using microsurgical scissor. After damage, the skin was sutured and the animals returned to cage to rest.

\section{PDRN Application}

PDRN (Recovery, Kyungbo Pharm Co., Asan, Korea) was injected directly into the injury site at respective dose in $100-\mu \mathrm{L}$ volume, once every 2 days for 16 days (total 6 times), starting 3 days after surgery. The effective concentrations of PDRN were selected based on the research by Kang et al. [15]

\section{von Frey Filament Test}

Mechanical allodynia was assessed by measuring the paw with- 
draw threshold, like the method described below [16,17]. The rat was tested for the von Frey filament test 1 day before surgery, 6 days, 11 days, and 15 days after Achilles tendon injury. The rat was picked into a clear acrylic box with a metal mesh on the bottom and left for at least 10 minutes until the exploratory action stopped. von Frey filaments (Stoelting Co., Illinois, IL, USA) with increasing stiffness $(0.40,0.60,1.00,1.40,2.00$, $4.00,8.00,15.00,26.00 \mathrm{~g}$ ) were applied sequentially to the sole of the right hind foot.

\section{Plantar Test}

Algesimeter (Ugo-Basile, Comerio, Italy) was used for the plantar test. The planta test was performed for the determination of thermal hyperalgesia 16 days after injury to the Achilles tendon, like the method described below [18]. The rat was placed in a clear acrylic box and, after acclimation, the planta test was started. Radiant heat was applied to the sole surface of the ipsilateral hind paw until the rat was hot and paw was lifted. When the rat lifts its paw, the photocell automatically turns off the heat source, and the time of seconds until this was calculated as the paw withdrawal latency.

\section{Tissue Preparation}

After performing the plantar test, tissue preparation was performed, like the method described below [19]. Tendon tissue was collected by removing the damaged Achilles tendon after anesthesia with Zoletil $50(10 \mathrm{mg} / \mathrm{kg}$, intraperitoneally; Vibac Laboratories). The collected Achilles tendon tissues were treated with $4 \%$ paraformaldehyde, ethanol, xylene, and then infiltrated in paraffin. Using a microtome (Thermo Co., Cheshire, $\mathrm{UK})$, coronal slices with $5-\mu \mathrm{m}$ thickness were made.

\section{H\&E Staining}

H\&E staining was done, like the method described below [13]. After immersing the slides in Mayer's hematoxylin (DAKO, Glostrup, Denmark) for 30 seconds, the slides were washed with water, immersed in eosin (Sigma Chemical Co., St. Louis, MO, USA) for 10 seconds, and then washed by running water. After drying the slides at room temperature, immersed 2 times in $95 \%$ ethanol, $100 \%$ ethanol, 50\% ethanol and 50\% xylene, and $100 \%$ xylene respectively. Permount (Fisher Scientific, Waltham, MA, USA) was finally used to mount the coverslips.

\section{Immunohistochemistry}

Immunohistochemistry for cleaved caspase-3-positive cells and cleaved caspase-9-positive cells was done, like the method described below [13]. The paraffin slides containing Achilles tendon tissues were deparaffinized by xylene, treated with ethanol, and rehydrated by water for 5 minutes. The Achilles tendon tissues were boiled in $10 \mathrm{mM}$ citric acid $(\mathrm{pH}, 6.0)$ for 10 minutes and treated with rabbit anticleaved caspase- 3 antibody or rabbit anticleaved caspase- 9 antibody (Abcam, Cambridge, UK) overnight at a dilution of 1:200. The sections were treated with biotinylated anti-rabbit secondary antibody (Vector Laboratories, Burlingame, CA, USA) for 1 hour and then treated with avidinbiotin-peroxidase complex (Vector Laboratories) at room temperature for 1 hour. The sections were treated with $0.05 \%$ 3,3'-diaminobenzidine and $0.01 \% \mathrm{H}_{2} \mathrm{O}_{2}$ in $50 \mathrm{mM}$ Tris-buffer $(\mathrm{pH}, 7.6)$ for 3 minutes for visualization of immunoreactivity. After air-drying the slides at room temperature overnight, Permount (Fisher Scientific) was finally used to mount the coverslips.

\section{Proinflammatory Cytokines and CAMP Concentrations}

ELISA was done to detect TNF- $\alpha$, IL- 6 , and cAMP concentrations in the Achilles tendon. Following the manufacturer's instruction, TNF- $\alpha$, IL-6, and cAMP concentrations were detected by enzyme immunoassay kit (Abcam), like the method described below [11].

\section{Western Blot Analysis}

Western blot analysis was done, like the method described below $[20,21]$. The Achilles tendon tissues were homogenized with lysis buffer containing $50 \mathrm{mM}$ Tris- $\mathrm{HCl}(\mathrm{pH}, 8.0), 100 \mathrm{mM}$ $\mathrm{NaF}, 150 \mathrm{mM} \mathrm{NaCl}, 1.5 \mathrm{mM} \mathrm{MgCl}_{2} \cdot 6 \mathrm{H}_{2} \mathrm{O}, 1 \mathrm{mM}$ EGTA, $1 \mathrm{mM}$ PMSF, $1 \mathrm{mM} \mathrm{Na}_{2} \mathrm{VO}_{4}, 10 \%$ glycerol, $1 \%$ Triton X-100, and then centrifuged for 30 minutes at 14,000 rpm. Rabbit CREB antibody (1:1,000; Abcam), rabbit phosphorylated CREB (p-CREB) antibody (1:1,000; Santa Cruz Biotechnology, Santa Cruz, CA, USA), rabbit PKA antibody (1:1,000; Santa Cruz Biotechnology), rabbit phosphorylated PKA (p-PKA) antibody (1:1,000; Santa Cruz Biotechnology), mouse Bax antibody (1:1,000; Santa Cruz Biotechnology), mouse Bcl-2 antibody (1:1,000; Santa Cruz Biotechnology), and mouse $\beta$-actin antibody (1:1,000; Santa Cruz Biotechnology) were chosen as the primary antibodies. Horseradish peroxidase-conjugated anti-mouse antibody (1:2,000; Vector Laboratories) for $\beta$-actin, Bax, Bcl-2, and anti-rabbit antibody (1:2000; Vector Laboratories) for CREB, pCREB, PKA, p-PKA were chosen as the secondary antibodies. Membrane transfer was carried out at $4^{\circ} \mathrm{C}$, and all other steps 
were conducted at room temperature. The bands were calculated by Molecular Analyst version 1.4.1 (Bio-Rad Laboratories, Hercules, CA, USA).

\section{Data Analysis}

Histological findings were observed and percentages of cleaved caspase-3-positie cells and caspase-9-positive cells in Achilles tendon tissue slices were counted by an Image-Pro Plus computer-assisted image analysis system (Media Cyberbetics Inc., Silver Spring, MD, USA) attached to an optical microscope (Olympus, Tokyo, Japan). For the counting of cleaved caspase3 -positive cells and cleaved caspase-9-positive cells, 5 fields were selected from each sample, and over 100 cells per field were calculated under $\times 200$ magnification. The percentage of cleaved caspase-3-positive cells or cleaved caspase-9-positive cells was counted according to the following equation: cleaved caspase-3-positive cells or caspase-9-positive cells number/total cell number $\times 100(\%)$. For the relative quantitative measurement, we set the result of the control group to 1.00 in western blotting. Statistical analysis used 1-way analysis of variance with Duncan post hoc test. Results were presented as mean \pm standard error of the mean, with $\mathrm{P}<0.05$ indicating statistically significant.

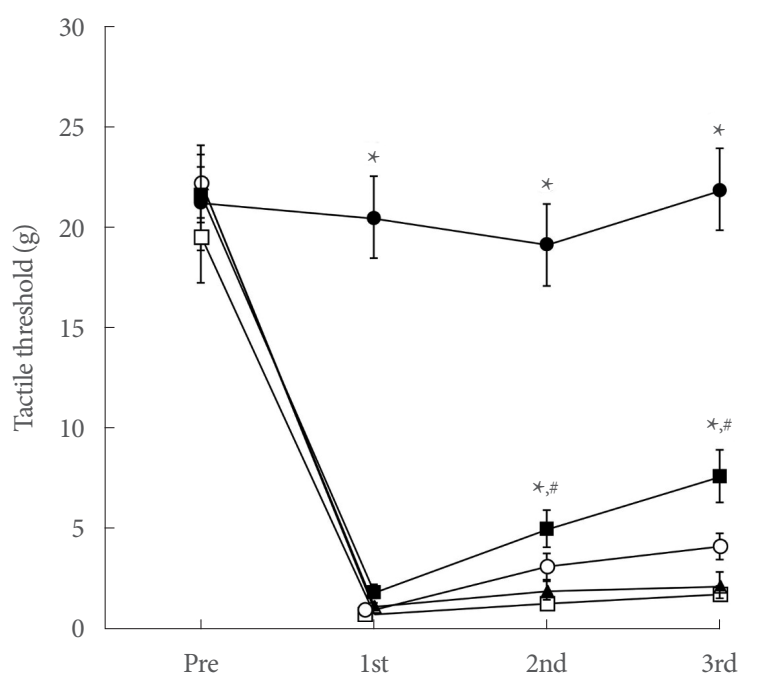

Fig. 1. Tactile threshold in von Frey filament test. •, control group; $\square$, Achilles tendon injury group; $\mathbf{\wedge}$, Achilles tendon injury and $2 \mathrm{mg} / \mathrm{kg}$ PDRN-applied group; $\odot$, Achilles tendon injury and $4 \mathrm{mg} / \mathrm{kg}$ PDRN-applied group; -, Achilles tendon injury and $8 \mathrm{mg} / \mathrm{kg}$ PDRN-applied group. PDRN, polydeoxyribonucleotide. ${ }^{*} \mathrm{P}<0.05$ compared with the control group. ${ }^{*} \mathrm{P}<0.05$ compared with the Achilles tendon injury group.

\section{RESULTS}

\section{Tactile Threshold in von Frey Filament Test}

The tactile threshold for the von Frey filament test is shown in Fig. 1. In the current study, tactile threshold of the control group maintained at the 20.0-g level during the experiment. Initially, the tactile threshold for all operation groups fell to near $1.00 \mathrm{~g}$ $(\mathrm{P}<0.05)$. In the Achilles tendon injury group, the tactile threshold gradually recovered during the experiment. However, in the Achilles tendon injury and $8 \mathrm{mg} / \mathrm{kg}$ PDRN-applied group, the tactile threshold was increased from the 11 days after surgery $(\mathrm{P}<0.05)$. On the 15 days after surgery, the tactile threshold was increased more potently in the Achilles tendon injury and $8 \mathrm{mg} /$ kg PDRN-applied group $(\mathrm{P}<0.05)$.

\section{Thermal Hyperalgesia in Plantar Test}

Thermal hyperalgesia presented by paw withdrawal latency is shown in Fig. 2. In the current study, induction of Achilles tendon injury reduced paw withdrawal latency in the plantar test $(\mathrm{P}<0.05)$, whereas PDRN application enhanced paw withdrawal latency $(\mathrm{P}<0.05)$.

\section{Concentrations of TNF- $a$ and IL- 6 in Achilles Tendon}

TNF- $\alpha$ and IL- 6 concentrations in Achilles tendon tissue are shown in Fig. 3. In the current study, TNF- $\alpha$ and IL- 6 concen-

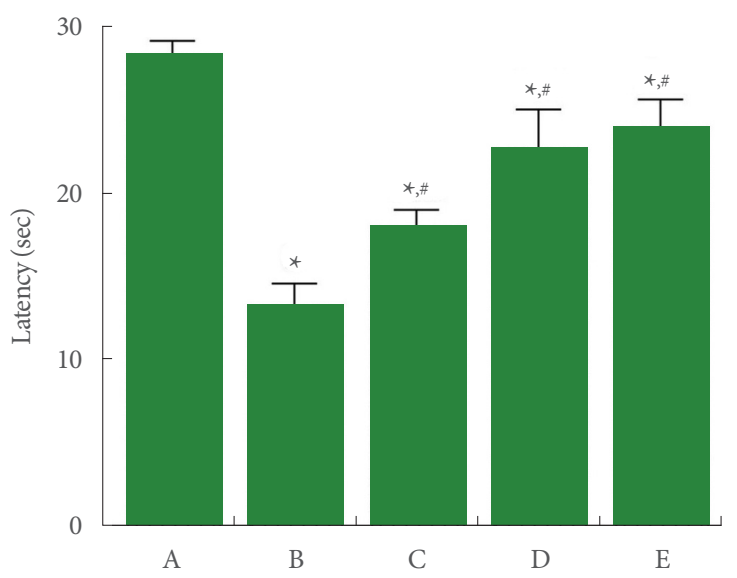

Fig. 2. Thermal hyperalgesia in plantar test. A, control group; B, Achilles tendon injury group; $\mathrm{C}$, Achilles tendon injury and 2 $\mathrm{mg} / \mathrm{kg}$ PDRN-applied group; D, Achilles tendon injury and 4 $\mathrm{mg} / \mathrm{kg}$ PDRN-applied group; E, Achilles tendon injury and 8 $\mathrm{mg} / \mathrm{kg}$ PDRN-applied group. PDRN, polydeoxyribonucleotide. ${ }^{*} \mathrm{P}<0.05$ compared with the control group. ${ }^{*} \mathrm{P}<0.05$ compared with the Achilles tendon injury group. 

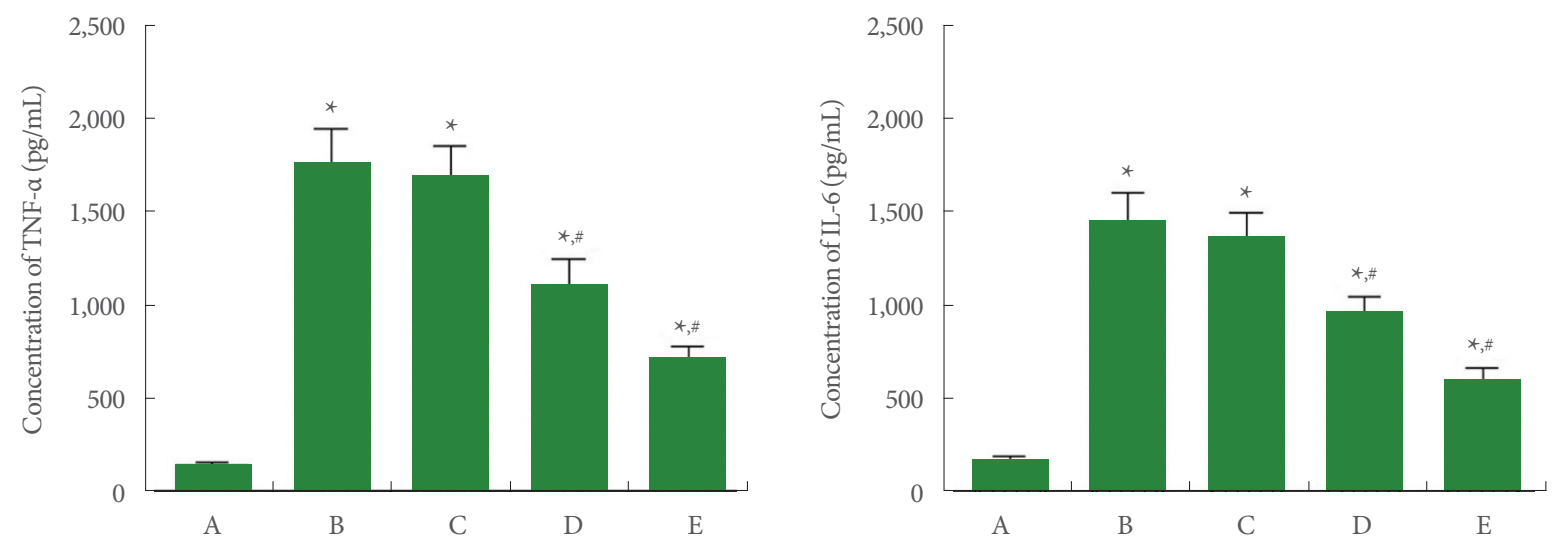

Fig. 3. Tumor necrosis factor (TNF)- $\alpha$ and interleukin (IL)-6 concentrations in Achilles tendon. Left panel: TNF- $\alpha$ concentration. Right panel: IL-6 concentration. A, control group; B, Achilles tendon injury group; C, Achilles tendon injury and 2 mg/kg PDRN-applied group; D, Achilles tendon injury and $4 \mathrm{mg} / \mathrm{kg}$ PDRN-applied group; E, Achilles tendon injury and $8 \mathrm{mg} / \mathrm{kg}$ PDRN-applied group. PDRN, polydeoxyribonucleotide. ${ }^{*} \mathrm{P}<0.05$ compared with the control group. ${ }^{*} \mathrm{P}<0.05$ compared with the Achilles tendon injury group.

trations were enhanced by Achilles tendon injury $(\mathrm{P}<0.05)$. In contrast, PDRN application inhibited TNF- $\alpha$ and IL- 6 concentrations $(\mathrm{P}<0.05)$.

\section{Concentration of cAMP in Achilles Tendon}

cAMP concentration in Achilles tendon tissue is shown in Fig. 4. In the current study, cAMP concentration was suppressed by Achilles tendon injury $(\mathrm{P}<0.05)$, whereas $\mathrm{PDRN}$ application enhanced cAMP expression $(\mathrm{P}<0.05)$.

\section{Ratio of $p$-CREB to CREB in Achilles Tendon}

The relative expression of CREB and p-CREB is shown in Fig. 5. In the current study, $\mathrm{p}$-CREB to CREB ratio was suppressed by Achilles tendon injury $(\mathrm{P}<0.05)$, whereas $\mathrm{PDRN}$ application increased $\mathrm{p}$-CREB to CREB ratio $(\mathrm{P}<0.05)$.

\section{Ratio of p-PKA to PKA in Achilles Tendon}

The relative expression of PKA and p-PKA is shown in Fig. 6. In the current study, $\mathrm{p}$-PKA to PKA ratio was suppressed by Achilles tendon injury $(\mathrm{P}<0.05)$. Meanwhile, $\mathrm{PDRN}$ application increased $\mathrm{p}-\mathrm{PKA}$ to $\mathrm{PKA}$ ratio $(\mathrm{P}<0.05)$.

\section{Expressions of Cleaved Caspase-3-Positive Cells and Cleaved Caspase-9-Positive Cells in Achilles Tendon}

The expressions of cleaved caspase-3-positive cells and cleaved caspase-9-positive cells are shown in Fig. 7. In the current study, expressions of cleaved caspase-3-positive cells and cleaved caspase-9-positive cells were enhanced by Achilles tendon injury

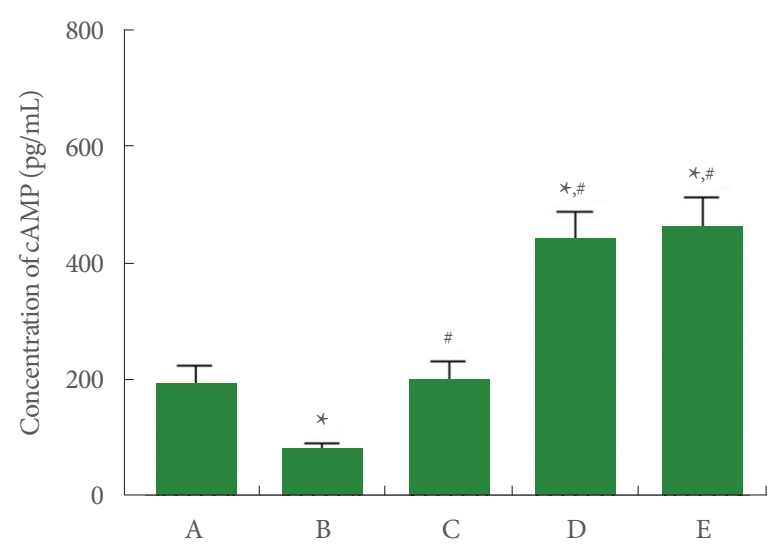

Fig. 4. Cyclic adenosine-3',5'-monophosphate (cAMP) concentration in Achilles tendon. A, control group; B, Achilles tendon injury group; $\mathrm{C}$, Achilles tendon injury and $2 \mathrm{mg} / \mathrm{kg}$ PDRN-applied group; D, Achilles tendon injury and $4 \mathrm{mg} / \mathrm{kg}$ PDRN-applied group; E, Achilles tendon injury and $8 \mathrm{mg} / \mathrm{kg}$ PDRN-applied group. PDRN, polydeoxyribonucleotide. ${ }^{*} \mathrm{P}<0.05$ compared with the control group. ${ }^{\#} \mathrm{P}<0.05$ compared with the Achilles tendon injury group.

$(\mathrm{P}<0.05)$. Meanwhile, PDRN application inhibited the expressions of cleaved caspase-3-positive cells and cleaved caspase9-positive cells $(\mathrm{P}<0.05)$.

\section{Expressions of Bax and Bcl-2 in Achilles Tendon}

The expressions of Bax and Bcl-2 are shown in Fig. 8. In the current study, Bax expression was increased $(\mathrm{P}<0.05)$ and $\mathrm{Bcl}-$ 2 expression was suppressed $(\mathrm{P}<0.05)$ by Achilles tendon injury, demonstrating an increased ratio of Bax versus Bcl-2 $(\mathrm{P}<$ 


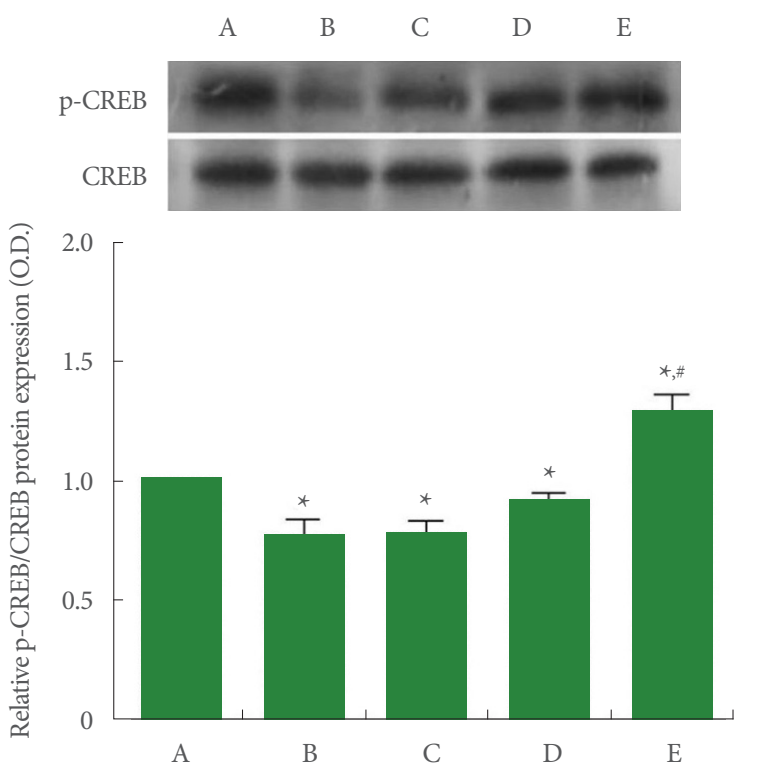

Fig. 5. Ratio of phosphorylated cAMP response element-binding protein (p-CREB) to CREB in Achilles tendon. Upper panel: representative expressions of $\mathrm{p}-\mathrm{CREB}$ and CREB. Lower panel: relative expression of p-CREB to CREB. A, control group; B, Achilles tendon injury group; $\mathrm{C}$, Achilles tendon injury and 2 $\mathrm{mg} / \mathrm{kg}$ PDRN-applied group; D, Achilles tendon injury and 4 $\mathrm{mg} / \mathrm{kg}$ PDRN-applied group; E, Achilles tendon injury and 8 $\mathrm{mg} / \mathrm{kg}$ PDRN-applied group. PDRN, polydeoxyribonucleotide. ${ }^{\star} \mathrm{P}<0.05$ compared with the control group. ${ }^{\#} \mathrm{P}<0.05$ compared with the Achilles tendon injury group.

0.05). In contrast, PDRN application inhibited Bax expression $(\mathrm{P}<0.05)$ and enhanced $\mathrm{Bcl}-2$ expression $(\mathrm{P}<0.05)$, showing inhibited ratio of $\mathrm{Bax}$ versus $\mathrm{Bcl}-2(\mathrm{P}<0.05)$.

\section{DISCUSSION}

Achilles tendon injury is a representative animal model causing mechanical allodynia and thermal hyperalgesia [22]. The von Frey filament test assesses sensitivity to pain responses using thin hair-like filaments of various diameters [23]. The plantar test evaluates the heat sensitivity and restoration of sensory function in rats [23]. In the current results, tactile threshold of the von Frey filament test and paw withdrawal latency of the plantar test were reduced after Achilles tendon insult. These results indicate that mechanical allodynia and thermal hyperalgesia occurred after Achilles tendon injury. In contrast, $8-\mathrm{mg} / \mathrm{kg}$ PDRN treatment alleviated mechanical allodynia and PDRN treatment relieved thermal hyperalgesia after Achilles tendon injury.

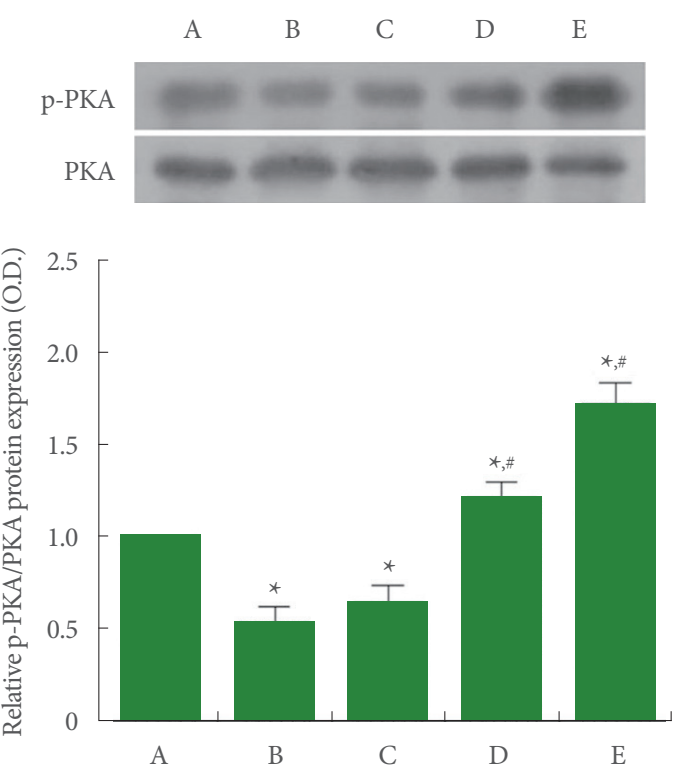

Fig. 6. Ratio of phosphorylated protein kinase A (p-PKA) to PKA in Achilles tendon. Upper panel: representative expressions of p-PKA and PKA. Lower panel: relative expression of $\mathrm{p}-$ PKA to PKA. A, control group; B, Achilles tendon injury group; C, Achilles tendon injury and $2 \mathrm{mg} / \mathrm{kg}$ PDRN-applied group; D, Achilles tendon injury and $4 \mathrm{mg} / \mathrm{kg}$ PDRN-applied group; E, Achilles tendon injury and $8 \mathrm{mg} / \mathrm{kg}$ PDRN-applied group. PDRN, polydeoxyribonucleotide. ${ }^{\star} \mathrm{P}<0.05$ compared with the control group. ${ }^{*} \mathrm{P}<0.05$ compared with the Achilles tendon injury group.

PDRN treatment decreased the expressions of proinflammatory cytokines such as IL-1 $\beta$, IL- 6 , and TNF- $\alpha$ [11]. In the current results, TNF- $\alpha$ and IL- 6 concentrations were enhanced after Achilles tendon injury, indicating that Achilles tendon injury was exacerbated due to overproduction of TNF- $\alpha$ and IL-6. However, PDRN application reduced TNF- $\alpha$ and IL- 6 concentrations in Achilles tendon injury.

The adenosine effects are manifested through $4 \mathrm{G}$ proteincoupled receptors, of which the adenosine $\mathrm{A}_{2 \mathrm{~A}}$ receptor suppresses proinflammatory cytokines secretion by CREB phosphorylation via the cAMP-PKA pathway $[9,24]$. Therefore, adenosine $A_{2 \mathrm{~A}}$ receptor agonists have been reported to be curable in the inflammation-related disorders $[11,25]$. In the current results, PDRN application enhanced cAMP concentration and p-CREB to CREB ratio, showing that PDRN facilitates phosphorylation of CREB and then activation of the CAMP-PKACREB pathway.

Tendon injury leads to degenerative changes by increasing caspases, Bax, and DNA fragmentation in tendon tissue $[3,26]$. 

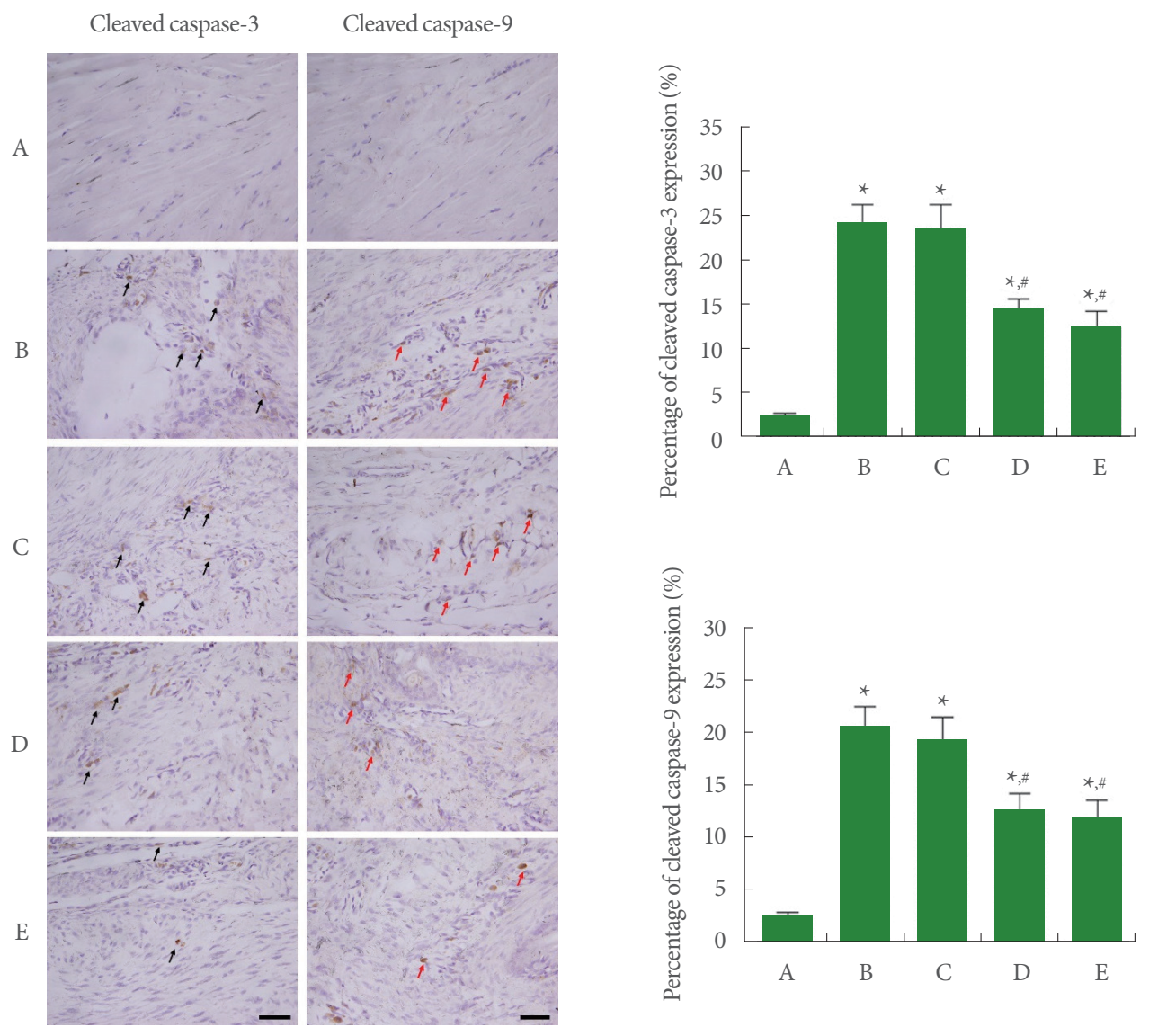

Fig. 7. Expressions of cleaved caspase-3 and caspase-9 in Achilles tendon. Left panel: photomicrographs of cleaved caspase-3-positive cells and cleaved caspase-9-positive cells. The sections were stained for cleaved caspase-3-positive cells (black arrows) and caspase9-positive cells (red arrows). The scale bar represents $250 \mu \mathrm{m}$. Right upper panel: percentage of cleaved caspase-3-positive cells. Right lower panel: percentage of cleaved caspase-9-positive cells. A, control group; B, Achilles tendon injury group; C, Achilles tendon injury and $2 \mathrm{mg} / \mathrm{kg}$ PDRN-applied group; D, Achilles tendon injury and $4 \mathrm{mg} / \mathrm{kg}$ PDRN-applied group; E, Achilles tendon injury and 8 $\mathrm{mg} / \mathrm{kg}$ PDRN-applied group. PDRN, polydeoxyribonucleotide. ${ }^{\star} \mathrm{P}<0.05$ compared with the control group. ${ }^{*} \mathrm{P}<0.05$ compared with the Achilles tendon injury group.

Apoptosis is associated with cellular degeneration of Achilles tendon injury, and tendon injury increases apoptotic activity with degenerative change [7]. In epileptic rats or rats with traumatic brain injury, the expression of Bcl-2 was suppressed and the expression of Bax was enhanced, causing an improvement of $\mathrm{Bax}$ to $\mathrm{Bcl}-2$ ratio, which initiates the apoptosis process $[8,27]$. PDRN suppressed apoptotic cell death in the gerbils with gastric ulcer, and cAMP exerts critical effect in regulating cell death by apoptosis [12]. In the current results, the percentages of cleaved caspase-3-positive cells and caspase-9-positive cells and the ratio of Bax versus Bcl-2 were enhanced after Achilles tendon injury, suggesting that Achilles tendon damage exacerbated apoptosis. In contrast, PDRN application inhibited the percentages of cleaved caspase-3-positive cells and caspase- 9-positive cells and the ratio of Bax versus Bcl-2 in Achilles tendon-injured rats.

The current study shows that PDRN treatment reduced pain sensitivity and improved histological degeneration in rats with Achilles tendon injury. PDRN treatment also suppressed inflammation and apoptosis in Achilles tendon injury. PDRN is probably believed to have a good effect on pain and inflammation in the urogenital organs. This study suggests that PDRN may be used as a new treatment for Achilles tendon injury.

\section{AUTHOR CONTRIBUTION STATEMENT}

- Conceptualization: JHR

- Data curation: JJJ, LH, SHK 

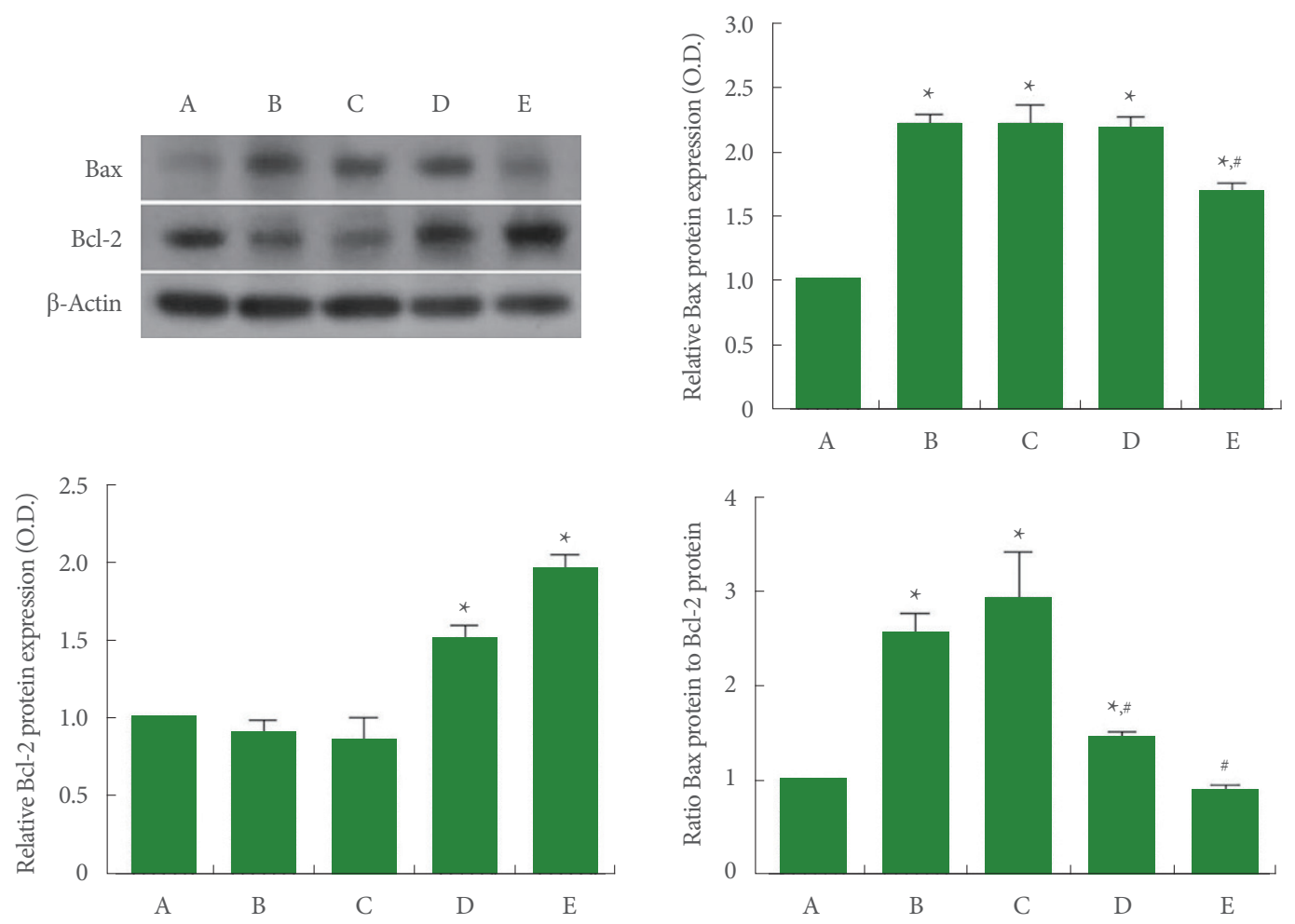

Fig. 8. Expressions of Bcl-2-associated X (Bax) and B-cell lymphoma 2 (Bcl-2) in Achilles tendon. Left upper panel: representative expressions of Bax and Bcl-2. Right upper panel: relative expression of Bax. Left lower panel: relative expression of Bcl-2. Right lower panel: ratio of Bax to Bcl-2. A, control group; B, Achilles tendon injury group; C, Achilles tendon injury and 2 mg/kg PDRN-applied group; D, Achilles tendon injury and $4 \mathrm{mg} / \mathrm{kg}$ PDRN-applied group; E, Achilles tendon injury and $8 \mathrm{mg} / \mathrm{kg}$ PDRN-applied group. PDRN, polydeoxyribonucleotide. ${ }^{\star} \mathrm{P}<0.05$ compared with the control group. ${ }^{*} \mathrm{P}<0.05$ compared with the Achilles tendon injury group.

- Formal analysis: JJJ, LH, SHK

- Funding acquisition: $\mathrm{JHH}$

- Methodology: JJJ, LH, SHK

- Project administration: $\mathrm{JHH}$

- Visualization: JYC, TJH

- Writing-original draft: $I G K$

-Writing-review \& editing: IGK

\section{REFERENCES}

1. Dakin SG, Newton J, Martinez FO, Hedley R, Gwilym S, Jones N, et al. Chronic inflammation is a feature of Achilles tendinopathy and rupture. Br J Sports Med 2018;52:359-67.

2. Jeong C, Kim SE, Shim KS, Kim HJ, Song MH, Park K, et al. Exploring the in vivo anti-inflammatory actions of simvastatin-loaded porous microspheres on inflamed tenocytes in a collagenase-induced animal model of Achilles tendinitis. Int J Mol Sci 2018;19: E820.
3. Pearce CJ, Ismail M, Calder JD. Is apoptosis the cause of noninsertional achilles tendinopathy? Am J Sports Med 2009;37:2440-44.

4. Inoue S, Browne G, Melino G, Cohen GM. Ordering of caspases in cells undergoing apoptosis by the intrinsic pathway. Cell Death Differ 2009;16:1053-61.

5. Kim YM, Jin JJ, Lee SJ, Seo TB, Ji ES. Treadmill exercise with bone marrow stromal cells transplantation facilitates neuroprotective effect through BDNF-ERK1/2 pathway in spinal cord injury rats. J Exerc Rehabil 2018;14:335-40.

6. Upadhyay D, Panduri V, Ghio A, Kamp DW. Particulate matter induces alveolar epithelial cell DNA damage and apoptosis: role of free radicals and the mitochondria. Am J Respir Cell Mol Biol 2003;29:180-7.

7. Bell R, Robles-Harris MA, Anderson M, Laudier D, Schaffler MB, Flatow EL, et al. Inhibition of apoptosis exacerbates fatigue-damage tendon injuries in an in vivo rat model. Eur Cell Mater 2018;36:4456.

8. Ko IG, Kim SE, Hwang L, Jin JJ, Kim CJ, Kim BK, et al. Late start- 
ing treadmill exercise improves spatial leaning ability through suppressing CREP/BDNF/TrkB signaling pathway following traumatic brain injury in rats. J Exerc Rehabil 2018;14:327-34.

9. Odashima M, Bamias G, Rivera-Nieves J, Linden J, Nast CC, Moskaluk $\mathrm{CA}$, et al. Activation of $\mathrm{A}_{2 \mathrm{~A}}$ adenosine receptor attenuates intestinal inflammation in animal models of inflammatory bowel disease. Gastroenterology 2005;129:26-33.

10. Veronesi F, Dallari D, Sabbioni G, Carubbi C, Martini L, Fini M. Polydeoxyribonucleotides (PDRNs) from skin to musculoskeletal tissue regeneration via adenosine A2A receptor involvement. J Cell Physiol 2017;232:2299-307.

11. Ko IG, Kim SE, Jin JJ, Hwang L, Ji ES, Kim CJ, et al. Combination therapy with polydeoxyribonucleotide and proton pump inhibitor enhances therapeutic effectiveness for gastric ulcer in rats. Life Sci 2018;203:12-19.

12. Jeon JW, Lee JI, Shin HP, Cha JM, Joo KR, Kim SH, et al. Adenosine $\mathrm{A}_{2 \mathrm{~A}}$-receptor agonist polydeoxyribonucleotide promotes gastric ulcer healing in Mongolian gerbils. Animal Cells Syst 2014;18:399406.

13. An J, Park SH, Ko IG, Jin JJ, Hwang L, Ji ES, et al. Polydeoxyribonucleotide ameliorates lipopolysaccharide-induced lung injury by inhibiting apoptotic cell death in rats. Int J Mol Sci 2017;18:E1847.

14. Freedman BR, Sarver JJ, Buckley MR, Voleti PB, Soslowsky LJ. Biomechanical and structural response of healing Achilles tendon to fatigue loading following acute injury. J Biomech 2014;47:2028-34.

15. Kang SH, Choi MS, Kim HK, Kim WS, Bae TH, Kim MK, et al. Polydeoxyribonucleotide improves tendon healing following achilles tendon injury in rats. J Orthop Res 2018;36:1767-76.

16. Dixon WJ. Staircase bioassay: the up-and-down method. Neurosci Biobehav Rev 1991;15:47-50.

17. Zhou C, Luo ZD. Electrophysiological characterization of spinal neuron sensitization by elevated calcium channel $\alpha-2-\delta-1$ subunit protein. Eur J Pain 2014;18:649-58.

18. Le Bars D, Gozariu M, Cadden SW. Animal models of nociception. Pharmacol Rev 2001;53:597-652.

19. Park SS, Kim TW, Kim CJ, Hong SY, Kim BK, Sim YJ, et al. Effect of sildenafil citrate on brain central fatigue after exhaustive swimming exercise in rats. J Exerc Rehabil 2019;15:651-6.

20. Song SH, Jee YS, Ko IG, Lee SW, Sim YJ, Kim DY, et al. Treadmill exercise and wheel exercise improve motor function by suppressing apoptotic neuronal cell death in brain inflammation rats. J Exerc Rehabil 2018;14:911-9.

21. Kim M, Kim TW, Kim CJ, Shin MS, Hong M, Park HS, et al. Berberine ameliorates brain inflammation in poloxamer 407-induced hyperlipidemic rats. Int Neurourol J 2019;23(Suppl 2):S102-10.

22. Christensen J, Alfredson H, Andersson G. Protease-activated receptors in the Achilles tendon-a potential explanation for the excessive pain signalling in tendinopathy. Mol Pain 2015;11:13.

23. Deuis JR, Dvorakova LS, Vetter I. Methods used to evaluate pain behaviors in rodents. Front Mol Neurosci 2017;10:284.

24. Haskó G, Linden J, Cronstein B, Pacher P. Adenosine receptors: therapeutic aspects for inflammatory and immune diseases. Nat Rev Drug Discov 2008;7:759-70.

25. Han JH, Jung J, Hwang L, Ko IG, Nam OH, Kim MS, et al. Anti-inflammatory effect of polydeoxyribonucleotide on zoledronic acidpretreated and lipopolysaccharide-stimulated RAW 264.7 cells. Exp Ther Med 2018;16:400-5.

26. Lui PP, Cheuk YC, Hung LK, Fu SC, Chan KM. Increased apoptosis at the late stage of tendon healing. Wound Repair Regen 2007; 15:702-7.

27. Lee JM, Ji ES, Kim TW, Kim CJ, Shin MS, Lim BV, et al. Treadmill exercise improves memory function by inhibiting hippocampal apoptosis in pilocarpine-induced epileptic rats. J Exerc Rehabil 2018;14:713-23. 